\title{
AN EPIDERMAL GROWTH FACTOR MOTIF OF DEVELOPMENTAL ENDOTHELIAL LOCUS 1 PROTEIN INHIBITS EFFICIENT ANGIOGENESIS IN EXPLANTED SQUAMOUS CELL CARCINOMA IN VIVO
}

\author{
Hisataka Kitano ${ }^{1 *}$, Atsushi Mamiya ${ }^{1}$, Tomomi Ishikawa ${ }^{1}$, Yusuke Fujiwara $^{1}$, Yoh Masaoka ${ }^{2}$, \\ TOSHIO MIKI ${ }^{2}$, AND CHIAKI HIDAI ${ }^{3}$ \\ Divisions of ${ }^{1}$ Oral Surgery and ${ }^{2}$ Physiology; and ${ }^{3}$ Medical Education Center, Nihon University School of Medicine, \\ Tokyo, Japan
}

\begin{abstract}
Background: Cancer gene therapy using a nonviral vector is expected to be repeatable, safe, and inexpensive, and to have longterm effectiveness. Gene therapy using the E3 and $\mathrm{C} 1$ (E3C1) domain of developmental endothelial locus-1 (Del1) has been shown to improve prognosis in a mouse transplanted tumor model. Objective: In this study, we examined how this treatment affects angiogenesis in mouse transplanted tumors. Materials and methods: Mouse transplanted tumors (SCCKN human squamous carcinoma cell line) were injected locally with a nonviral plasmid vector encoding E3C1 weekly. Histochemical analysis of the transplanted tumors was then performed to assess the effects of $\mathrm{E} 3 \mathrm{C} 1$ on prognosis. Results: All mice in the control group had died or reached an endpoint within 39 days. In contrast, one of ten mice in the E3C1 group had died by day 39, and eight of ten had died or reached an endpoint by day 120 ( $p<0.01$ ). Enhanced apoptosis in tumor stroma was seen on histochemical analyses, as was inhibited tumor angiogenesis in E3C1-treated mice. In addition, western blot analysis showed decreases in active Notch and HEY1 proteins. Conclusion: These findings indicate that cancer gene therapy using a nonviral vector encoding E3C1 significantly improved life-span by inhibiting tumor angiogenesis. (REV INVEST CLIN. 2021;73(1):39-51)
\end{abstract}

Key words: Cancer Gene Therapy. Developmental Endothelial Locus-1. Tumor Angiogenesis. Tumor Stroma.

\section{INTRODUCTION}

The number of patients globally with head and neck cancers is increasing, with approximately 890,000 cases and 450,000 deaths annually in $2018^{1,2}$. Head and neck cancer occur in various regions, including the lips, nose, paranasal sinuses, major salivary glands, and other structures. Squamous cell carcinoma is the most common histopathological type in oral head and neck cancers. The stage of oral cancer at diagnosis is highly correlated with the likelihood of survival, but currently, only $31 \%$ of oral cancer cases are diagnosed
*Corresponding author:

Hisataka Kitano

E-mail: kitano.hisataka@nihon-u.ac.jp
Received for publication: 14-05-2020

Approved for publication: 15-08-2020

DOI: 10.24875/RIC.20000375

0034-8376 / (C) 2020 Revista de Investigación Clínica. Published by Permanyer. This is an open access article under the CC BY-NC-ND license (http://creativecommons.org/licenses/by-nc-nd/4.0/). 
at an early stage ${ }^{3,4}$. The diagnosis of oral cancer cases at late-stage results in 5-year overall survival rates ranging from $30 \%$ to $50 \%{ }^{4}$. At present, oral cancer is mainly treated with surgery, chemotherapy, radiation therapy, and combination therapy, but such treatments can be ineffective. In contrast, cancer gene therapy holds promise as a new treatment strategy ${ }^{5-9}$. In 1991, the first clinical trial of cancer gene therapy demonstrated that genetically modified immune cells can be successfully reintroduced into patients ${ }^{10,11}$, and subsequent approval of chimeric antigen receptor T cell therapy by the US Food and Drug Administration resulted in remarkable advances in this field.

Kitano et al. ${ }^{12,13}$ attempted gene therapy against explanted squamous cell carcinoma in vivo. Mouse transplanted tumors were treated with the extracellular matrix protein developmental endothelial locus-1 (Del1) using a nonviral vector. Del1 is an extracellular matrix protein secreted by embryonic endothelial cells and hypertrophic chondrocytes ${ }^{14}$ and is reported to affect angiogenesis or anti-angiogenesis, depending on the experimental method ${ }^{14}$. Del1 consists of five domains: three epidermal growth factor (EGF) repeats (E1, E2, and E3) and two discoidin domains ( $\mathrm{C} 1$ and $\mathrm{C} 2)^{14}$. E2 contains arginine-glycineaspartic acid (RGD) sequences, which bind to integrin receptors and support endothelial cell survival ${ }^{14}$. E3 induces endocytosis and increases the efficiency of gene transfer and has been reported to induce apoptosis ${ }^{15,16}$. $\mathrm{C} 1$ has been shown to be deposited in the extracellular matrix ${ }^{17}$. Given these reports, we hypothesized that a recombinant protein consisting of the E3 and C1 (E3C1) domains of Del1 would be deposited in the extracellular matrix of tumor cells and induce apoptosis. In addition, we anticipated that E3C1 would increase the efficiency of transfection. The present investigation involved weekly local injections of DNA encoding recombinant $\mathrm{E} 3 \mathrm{C} 1$ protein in a nonviral vector into mice, each with an explanted tumor created using the SCCKN human squamous carcinoma cell line ${ }^{13}$. We previously observed efficient deposition of $\mathrm{E} 3 \mathrm{C} 1$ and improved gene transfer efficiency in tumors ${ }^{13}$, with $50 \%$ of the E3C1-treated mice surviving for at least 7 weeks but all control mice dying ${ }^{13}$. In addition, analysis of the results of longterm treatment with E3C1 revealed that $20 \%$ of E3C1-treated mice survived for at least 197 days and that the explanted tumors had disappeared in two of the ten E3C1-treated mice by day 19718. Further, in another study using A431 squamous cell carcinoma cells ${ }^{18}$, all E3C1-treated mice survived for at least 39 days, whereas all control mice died or were euthanized.

The mechanism of anti-angiogenic therapy (AAT) is to inhibit tumor angiogenesis, thereby starving the tumor. In contrast, the disruption of tumor vessels using AAT has proven to be less successful ${ }^{19,20}$. The advantage of AAT is that it is transitory. Moreover, treated tumors have been reported to relapse into various forms of vasculogenesis, including vascular connections, endothelial angiogenesis, and vasculogenic mimicry ${ }^{21-25}$. In addition, in tumors treated with AAT, the tumor vasculature has been shown to exhibit a leak-free barrier, making these tissues more susceptible to tumor cell invasion and metastasis, causing the promotion of acquired resistance to $\mathrm{AAT}^{24,25}$, and resulting in a leading cause of cancerrelated death worldwide ${ }^{26}$.

The purpose of this study was to investigate the effects of treatment with $\mathrm{E} 3 \mathrm{C} 1$ on tumor angiogenesis. Mouse transplanted tumors were consecutively treated using E3C1 until a humane endpoint (conducted in accordance with the animal study committee at Nihon University). The mechanisms underlying the antivasculogenic effects of treatment with $\mathrm{E} 3 \mathrm{C} 1$ were then investigated in both in vivo and in vitro experiments.

\section{MATERIALS AND METHODS}

\section{Cell lines and culture}

The SCCKN (RIKEN BioResource Research Center, Tokyo, Japan, cell number: RCB0441)27,28 human squamous carcinoma cell line was kindly provided by $\mathrm{Dr}$. Hayashido from the University of Hiroshima in Hiroshima, Japan. This cell line was grown in RD medium, which was composed of 45\% Dulbecco's modified Eagle's medium (Invitrogen, Carlsbad, CA), 45\% RPMI 1640 medium (Invitrogen), and 10\% fetal bovine serum. The cells were then cultured in $5 \% \mathrm{CO}_{2}$ at $37^{\circ} \mathrm{C}$.

\section{DNA constructs}

Mouse Del1 complementary DNA was donated by Dr. Quertermous from Stanford University (Stanford, CA). 
A fragment encoding $\mathrm{E} 3 \mathrm{C} 1$ (amino acids $122-316$ of mouse Del1) was amplified using polymerase chain reaction (PCR) with the forward primer 5'-TGTGAAGCTGAGCCTTGCAGAATGGCCGGA-3' and the reverse primer 5'-ACAGCCTGAGAGCTCACAGCCAAGAAGTT-3' to generate pcDNA3.1D (Invitrogen), a mammalian expression vector. The signal peptide sequences of Del1 and E3C1 complementary DNA were inserted into pcDNA3.1D, a mammalian expression vector (Invitrogen). Recombinant proteins expressed by the construct showed V5-epitope tags at the C-terminal ends.

\section{Animal studies}

All animal experiments described in this study were carried out in accordance with both Nihon University and US National Institutes of Health animal care regulations. This study was approved by the Ethics Committee of Nihon University (AP13M045). A pathogen-free environment was provided for the rearing of $\mathrm{Nu} / \mathrm{Nu}$ athymic nude mice. For tumor transplants, SCCKN cells were first seeded in $10-\mathrm{cm}$ culture dishes overnight to reach $70-80 \%$ confluence, then harvested using a cell stripper (Asone, Tokyo, Japan) after washing with phosphate-buffered saline (PBS). After the cells were washed twice with PBS, they were centrifuged at $500 \times \mathrm{x}$ for $5 \mathrm{~min}$. The cells were then resuspended in RD medium at a concentration of $1 \times 10^{7 / 100} \mu \mathrm{L}$. Explantation of SCCKN sometimes failed if lower cell concentrations were used (data not shown). Nude mice were injected subcutaneously with a total of $100 \mu \mathrm{L}$ of cell suspension in the right dorsal region (mock treatment, $\mathrm{n}=5$; E3C1 treatment, $n=10$ ). After the tumor was explanted, mice were randomly assigned to the control group or E3C1-treated group. Mice were monitored twice weekly for tumor growth. When tumors were observed, their size was measured in two perpendicular dimensions using calipers. Tumor volume (in cubic millimeters) was calculated using the formula: tumor volume $=\left(\right.$ width $\times$ length $\left.{ }^{2}\right) / 2$. Treatment with either plasmid encoding $\mathrm{E} 3 \mathrm{C} 1 \mathrm{(pE} 3 \mathrm{C} 1)$ or pcDNA3 as a mock vector was started when the tumor volume exceeded $60 \mathrm{~mm}^{3}$ by injecting $10 \mu \mathrm{g}$ of DNA into the tumor in 100- $\mu \mathrm{L}$ increments using an in vivo-jetPEI (Polyplus-Transfection, San Marcos, CA) once a week. When the tumor volume exceeded $5000 \mathrm{~mm}^{3}$ (approximately $>15 \%$ of body weight), the mouse was considered to have reached an endpoint and was euthanized. The observation period ended on day 120 .

On the other hand, 4 weeks after the start of treatment, another six mice (mock treatment, $\mathrm{n}=3 ; \mathrm{E} 3 \mathrm{C} 1$ treatment, $\mathrm{n}=3$ ) were sacrificed under deep anesthesia with isoflurane for histological experiments, the tumors were immediately removed and frozen at $-80^{\circ} \mathrm{C}$, then $5-\mu \mathrm{m}$ frozen sections were prepared.

\section{Transmission electron microscopy}

Cells were fixed overnight in $2.5 \%$ glutaraldehyde in $0.1 \mathrm{M}$ cacodylic buffer $(\mathrm{pH} 7.4)$, then fixed with $1 \%$ osmium tetroxide in $0.1 \mathrm{M}$ cacodylic buffer $(\mathrm{pH} 7.4$ ) for $2 \mathrm{~h}$. Finally, the cells were dehydrated using a gradient ethanol series and embedded in Quetol-812. Ultrathin sections made using a diamond knife ultramicrotome (Ultracut UCT; Leica, Vienna, Austria) were stained with uranyl acetate and lead citrate, then observed with a transmission electron microscope (JEM-1200EX; JEOL, Tokyo, Japan).

\section{Evaluation of perfusion}

Six mice (mock treatment, $\mathrm{n}=3$; E3C1 treatment, $\mathrm{n}=3$ ) received an intravenous injection of India ink, then euthanized after 2 min. Transplanted tumors were immediately fixed in $4 \%$ paraformaldehyde (PFA). Furthermore, another six mice (mock treatment, $\mathrm{n}=3$; E3C1 treatment, $\mathrm{n}=3$ ) received an intravenous injection of fluorescein-conjugated Lycopersicon esculentum (tomato) lectin $(0.4 \mathrm{mg} / \mathrm{mL}$ ) (Vector Laboratories, Burlingame, CA). The mice were euthanized $2 \mathrm{~min}$ after the injection. The transplanted tumors were immediately resected and placed in OCT compound (Sakura Finetek Japan, Tokyo, Japan) and the blocks were stored at $-80^{\circ} \mathrm{C}$.

\section{Reagents}

Recombinant fusion proteins with alkaline phosphatase (AP) were prepared as follows ${ }^{15,17}$. Reverse transcription-PCR (RT-PCR) was used to generate the E3C1 fragment. AP-tagged E3C is a protein secreted in Chinese hamster ovary cells cultured in 64 medium (60\% Opti-MEM and 40\% LHC-8 medium; Invitrogen) and was produced by cloning the $\mathrm{E} 3 \mathrm{C} 1$ fragment into the AP-tag4 vector (GenHunter, Nashville, TN). Conditioned medium used as a control was created using 
an AP tag without E3C1. AP activity in the conditioned medium was investigated by adding $10 \mu \mathrm{L}$ of $0.05 \%$ Zwittergent (Calbiochem, La Jolla, CA) in PBS to $20 \mu \mathrm{L}$ of conditioned medium. The plates were heated to $65^{\circ} \mathrm{C}$ for $30 \mathrm{~min}$ to inactivate endogenous AP. The enzymatic reaction was initiated by adding $200 \mu \mathrm{L}$ of substrate $(1 \mathrm{mg} / \mathrm{mL}$ p-nitrophenyl phosphate [Sigma-Aldrich, St Louis, MO] in $1 \mathrm{mM} \mathrm{MgCl}$ and $1 \mathrm{M}$ diethanolamine, $\mathrm{pH}$ 9.8) to each well, then after $30 \mathrm{~min}$, each well was illuminated at $405 \mathrm{~nm}$ and its absorbance was measured. The molarity of APtagged recombinant proteins was calculated based on results obtained using AP purchased from Wako (Tokyo, Japan) as a standard.

\section{Immunohistochemistry}

Rabbit polyclonal von Willebrand factor antibody (Abcam, Cambridge, England), anti-CD31 (PECAM) antibody (Abcam), anti-platelet-derived growth factor (PDGF)-beta antibody (Abcam), and anti-alpha smooth muscle actin (aSMA) antibody (Abcam) were purchased, and Alexa Fluor 488- or Alexa Fluor 568-labeled goat anti-rabbit antibodies from Invitrogen were used. The $5-\mu \mathrm{m}$ sections were fixed in $4 \%$ PFA, then incubated with primary antibodies for immunohistochemistry and appropriate secondary antibodies. An Axioskop 2 microscope (Carl Zeiss Microimaging, Welwyn Garden City, UK) equipped with an AxioCam (Carl Zeiss Microimaging) was used to observe tissues and take photographs. Fluorescence intensity was measured using Photoshop version 7.0 software (Adobe Systems Incorporated, San Jose, CA). The intensities of control samples were designated as 1 . The results per view are expressed as mean \pm standard deviation (SD).

\section{In situ detection of DNA fragmentation}

In situ DNA fragmentation was detected in 5- $\mu \mathrm{m}$ frozen sections using a TACS2 TdT-blue labeled in situ detection kit (Trevigen, Gaithersburg, MD), then nuclear fast red was used to counter-stain the tissue.

\section{Western blot}

A 35-mm diameter dish was used to culture the cells overnight, then $1 \mathrm{pmol} / \mathrm{mL}$ of AP or AP-tagged E3C1 was added to the culture medium daily. Cells were harvested using sample buffers appropriate for the experiment. The samples were separated by sodium dodecyl sulfate-polyacrylamide gel electrophoresis, then transferred to a polyvinylidene difluoride membrane (ATTO, Tokyo, Japan). The membranes were incubated with primary antibodies, then incubated with horseradish peroxidase-conjugated secondary antibodies. Immunoreactive proteins were then detected using an ECL Advance Western blotting detection kit (Amersham, Piscataway, NJ).

\section{Statistical analysis}

Survival analysis was performed using the KaplanMeier method with a generalized Wilcoxon test. The results of all analyses are expressed as mean \pm SD. The Wilcoxon rank-sum test was performed as appropriate, and $p<0.05$ were considered statistically significant.

\section{RESULTS}

Mice with transplanted tumors treated using gene therapy. The effect of $\mathrm{E} 3 \mathrm{C} 1$ treatment on the distribution of exogenous proteins was observed by immunohistochemistry. In control tumors (Fig. 1A and C), no exogenous protein was detected on day 7 . In contrast, exogenous protein was observed in the stroma of tumors in mice treated with pE3C1 (Fig. 1B and D). Treatment with $\mathrm{pE} 3 \mathrm{C} 1$ improved life prognosis (Fig. 1E) and suppressed the growth of explanted tumors (Fig. $1 \mathrm{~F}-\mathrm{H}$ ) in mice. In the control group, the mice started to die from day 15 , and all mice had died or reached an endpoint by day 39 (Fig. 1E). Mice in the $\mathrm{E} 3 \mathrm{C} 1$ group started to die from day 39 , and by day 120,8 of 10 mice had died or reached an endpoint (Fig. 1E). The two remaining mice survived until the end of the observation period. The survival rate was significantly higher for mice in the $\mathrm{E} 3 \mathrm{C} 1$-treated group than in the control group $\left(p=2.14 \times 10^{-3}\right)$. Mice in the control group showed an exponential increase in tumor volume (Fig. 1F). The tumor growth curve of the $\mathrm{E} 3 \mathrm{C} 1$-treated mice differed from that of the control mice. In the E3C1-treated mice, tumor volume increased slowly during the treatment period and intermittently increased with two-volume reductions (Fig. 1G). The two surviving E3C1-treated mice were free of tumors as of days 29 and 43 and thus 
Figure 1. Changes caused by gene therapy using E3C1. (A) Exogenous proteins and nuclei are visualized in green and blue, respectively. Control ( $A$ and $\mathbf{C}$ ) and pE3C1 (B and $\mathbf{D}$ ) on day 7. (E) Kaplan-Meier survival curves of mice in the control group (solid line, $n=5)$ and mice in the $\mathrm{E} 3 \mathrm{C} 1$ treatment group (dashed line, $\mathrm{n}=10)(\mathrm{p}<0.01)$. ( $\mathrm{F}$ and $\mathrm{G})$ Chronological changes in tumor volume in individual mice in the control group (F) and E3C1 group (G). (H) Tumor volumes were compared after 14 days of treatment. The results are expressed as mean \pm SD. ${ }^{* *} \mathrm{p}<0.01$. (I and J) After 28 days of treatment, transplanted tumors were stained with hematoxylin and eosin in the control group (I) and $\mathrm{E} 3 \mathrm{C} 1$ group (J) ( $5 \mu$ objective lens). Arrows indicate necrotic lesions. Scale bars, $50 \mu \mathrm{m}$. (K and $\mathrm{L}$ ) Apoptosis in tumors was detected by DNA fragmentation staining for the control group (K) and $\mathrm{E} 3 \mathrm{C} 1$ group (L) on day 28. Arrows indicate DNA fragmentation lesions. Scale bars, $50 \mu \mathrm{m}$.
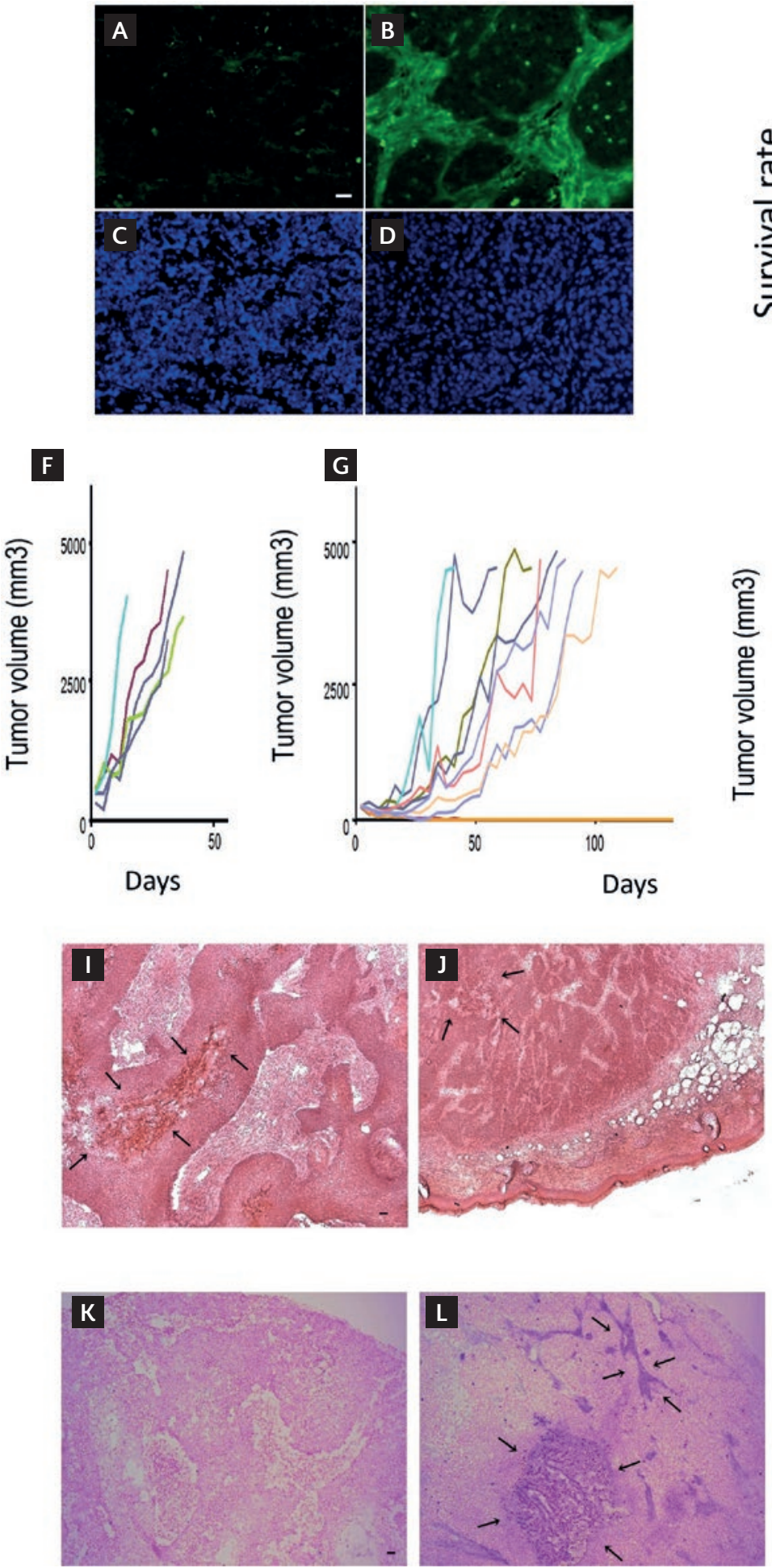
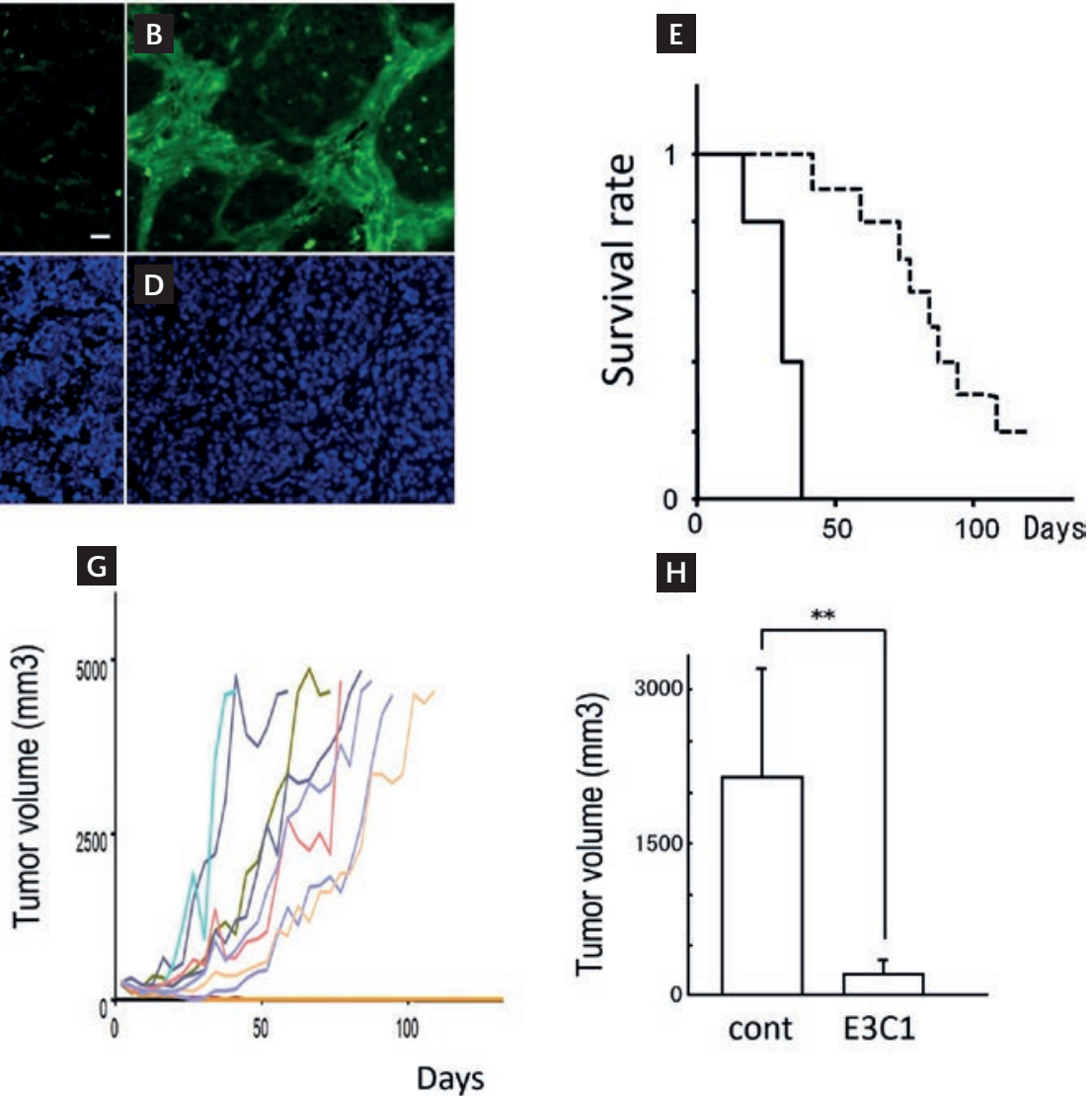
observation was discontinued. Mean tumor volumes were compared at day 14 because the mice started to die from day 15 after initiating treatment. Mean tumor volumes on day 14 were $2133 \pm 1130 \mathrm{~mm}^{3}$ in the control mice and $203 \pm 167 \mathrm{~mm}^{3}$ in the E3C1treated mice $\left(p=2.1 \times 10^{-3}\right)($ Fig. $1 \mathrm{H})$.

Tumors at day 28 in the E3C1-treated mice were observed using hematoxylin and eosin staining (Fig. 1l and J). Tumors in the E3C1-treated and control mice were composed of parenchyma and stroma. Tumors in the control mice showed cell death in the parenchymal regions. Regions of cell death were postulated to be due to necrosis caused by poor oxygen and nutraceutical supplies. In contrast, cell death in tumors in the E3C1-treated mice showed no relation to the parenchymal pattern. Tumors from the mice treated for 28 days were stained for DNA fragmentation analysis (Fig. $1 \mathrm{~K}$ and $\mathrm{L}$ ). DNA fragmentation was not observed in control tumors, whereas tumors from the $\mathrm{E} 3 \mathrm{C} 1$-treated mice showed strong cell staining in the stroma.

\section{The vasculature in transplanted tumors was affected by gene therapy}

Injection of India ink through the caudal vein on day 28 showed that the tumor vessels in control mice had numerous branches (Fig. 2A and C). In contrast, tumor vessels in the E3C1-treated mice were large, with fewer small branches (Fig. 2B and D). Tumor vessels from the control and E3C1-treated mice were observed using electron microscopy. Endothelial cells in tumor vessels from the control mice appeared integrated and pericytes were observed outside the vessels (Fig. 2E and G), whereas the tumor vessels of E3C1-treated mice showed gaps between endothelial cells, wrecking the vascular lumen. In addition, the presence of pericytes was not clearly defined (Fig. $2 \mathrm{~F}$ and $\mathrm{H}$ ).

\section{The vasculature in transplanted tumors was observed to evaluate the effect of gene therapy}

The mice received an intravenous injection of lectin through the caudal vein on day 28 . Sections from the tumor were then stained using anti-von Willebrand factor for endothelial cells. In tumors from the control mice, vessels stained with anti-von Willebrand factor were filled with lectin (Fig. 3A-E), whereas the vessels in the $\mathrm{E} 3 \mathrm{C} 1$-treated mice were not filled with lectin (Fig. 3B-F).

In addition, we examined the localization of PECAM as an endothelial cell marker and PDGF-beta as a marker of tip cells. Samples of the E3C1-treated mice (Fig. 4A-E) showed increased fluorescence intensity of PDGF-beta staining compared with control mice (Fig. 4B-F). The fluorescence intensity of samples from the control mice was $1 \pm 0.8$, compared with $10.63 \pm 4.49$ in the E3C1-treated mice $(p=4.77 \times$ $10^{-7}$ ) (Fig. 4G).

Next, we examined the localization of PECAM and aSMA. Anti-aSMA-positive cells were identified around anti-PECAM-positive cells in the control mice (Fig. 5A, C and E). In contrast, the number of aSMApositive cells was decreased or the cells were essentially absent in the E3C1-treated mice (Fig. 5B, D and F). The fluorescence intensity of aSMA was $12.31 \pm$ 5.93 in samples from the control mice and $1 \pm 0.6$ in samples from the E3C1-treated mice $\left(p=5.1 \times 10^{-7}\right)$ (Fig. 5G).

\section{The effects of $\mathrm{E} 3 \mathrm{C} 1$ on a-Notch target gene were evaluated by western blot}

Human umbilical endothelial cells cultured with APtagged recombinant-control protein or AP-tagged recombinant-E3C1 recombinant protein were analyzed by western blotting using anti-active Notch and anti-HEY1 antibody. E3C1-treated cells showed decreased expression of active Notch after 5 min and decreased expression of active Hey 1 after $10 \mathrm{~min}$ (Fig. 6A). The density of active Notch was $1 \pm 0.03$ in samples of the control cells and $0.46 \pm 0.06$ in samples of the E3C1-treated cells at $5 \mathrm{~min}\left(\mathrm{p}=1.85 \times 10^{-4}\right)$ (Fig. 6B), and the density of Hey1 was $1 \pm 0.03$ and $0.91 \pm 0.03$ in samples of the control cells and E3C1treated cells, respectively ( $p=0.02)$ (Fig. 6B).

\section{DISCUSSION}

Cancers often show numerous nutrient vessels from surrounding tissues that receive oxygen and nutrients. Therefore, if cancer angiogenesis is inhibited, cancer proliferation and/or metastasis could be better controlled ${ }^{23}$ and cancer might be maintained in a 
Figure 2. Vasculature in explanted tumors. (A and B) Nude mice with an explanted tumor were injected with India ink after gene therapy. Control (A) and pE3C1-treated mice (B) on day 28. (C and D) Enlarged images of the regions shown in A and B, respectively. Scale bars, $50 \mu \mathrm{m}$. The vasculature in the explanted tumors was observed under electron microscopy. (E and $\mathbf{F}$ ) Control (E) and pE3C1-treated (F) tumors on day 28. ( $G$ and $H$ ) Enlarged images of the regions shown in $E$ and $F$, respectively. Scale bars, $50 \mu \mathrm{m}$. E: endothelial cells; P: pericytes.
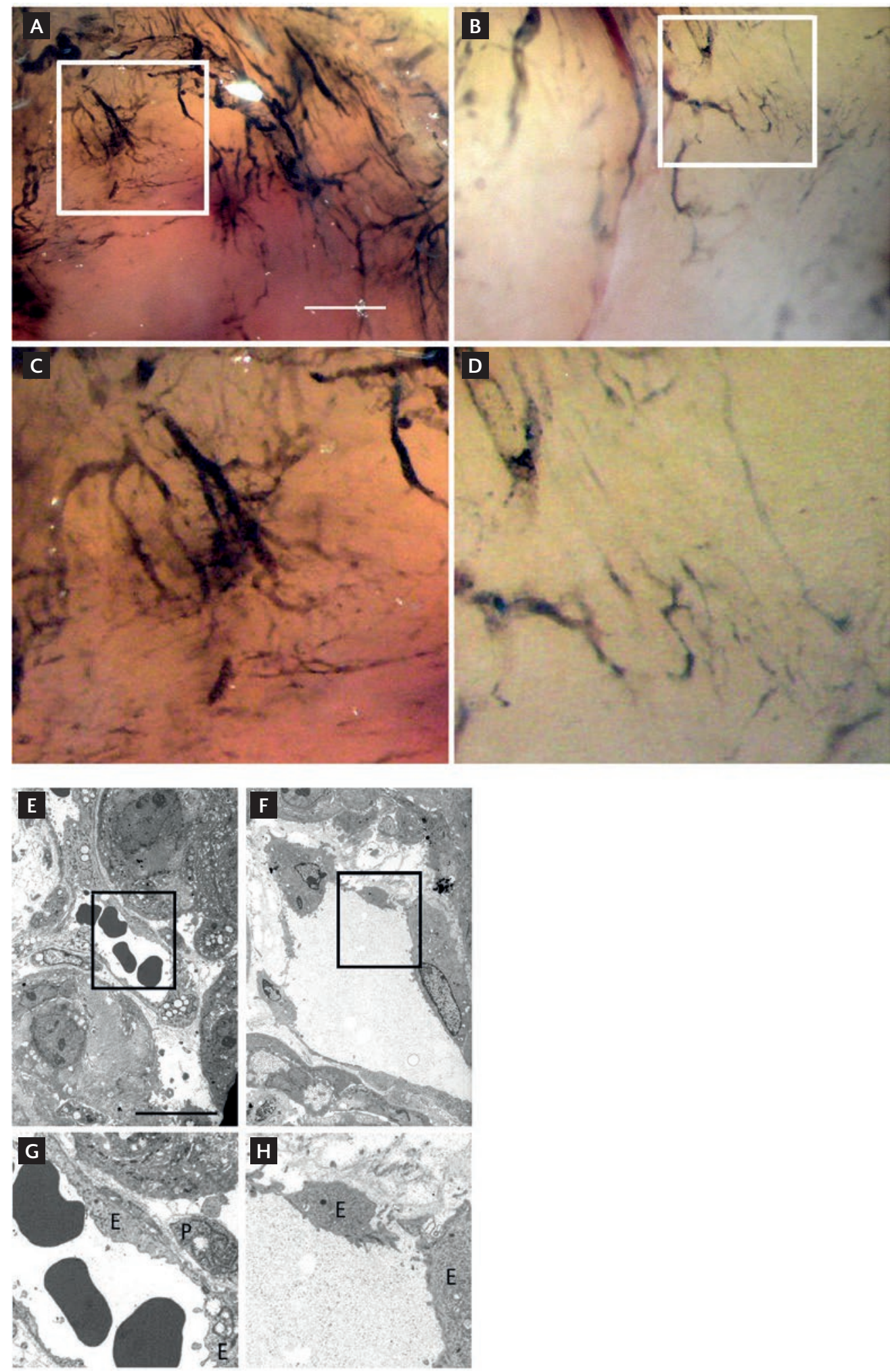
Figure 3. Evaluation of efficient vessels with lumen in the tumors. Nude mice with explanted tumors were injected with Lycopersicon esculentum (tomato) lectin after gene therapy (green). Specimens of the explanted tumor were stained for immunohistochemistry using anti-von Willebrand factor antibody (red). Control (A-E) and pE3C1-treated tumors (B-F) on day 28. Magnification, 20x. Scale bars, $50 \mu \mathrm{m}$.
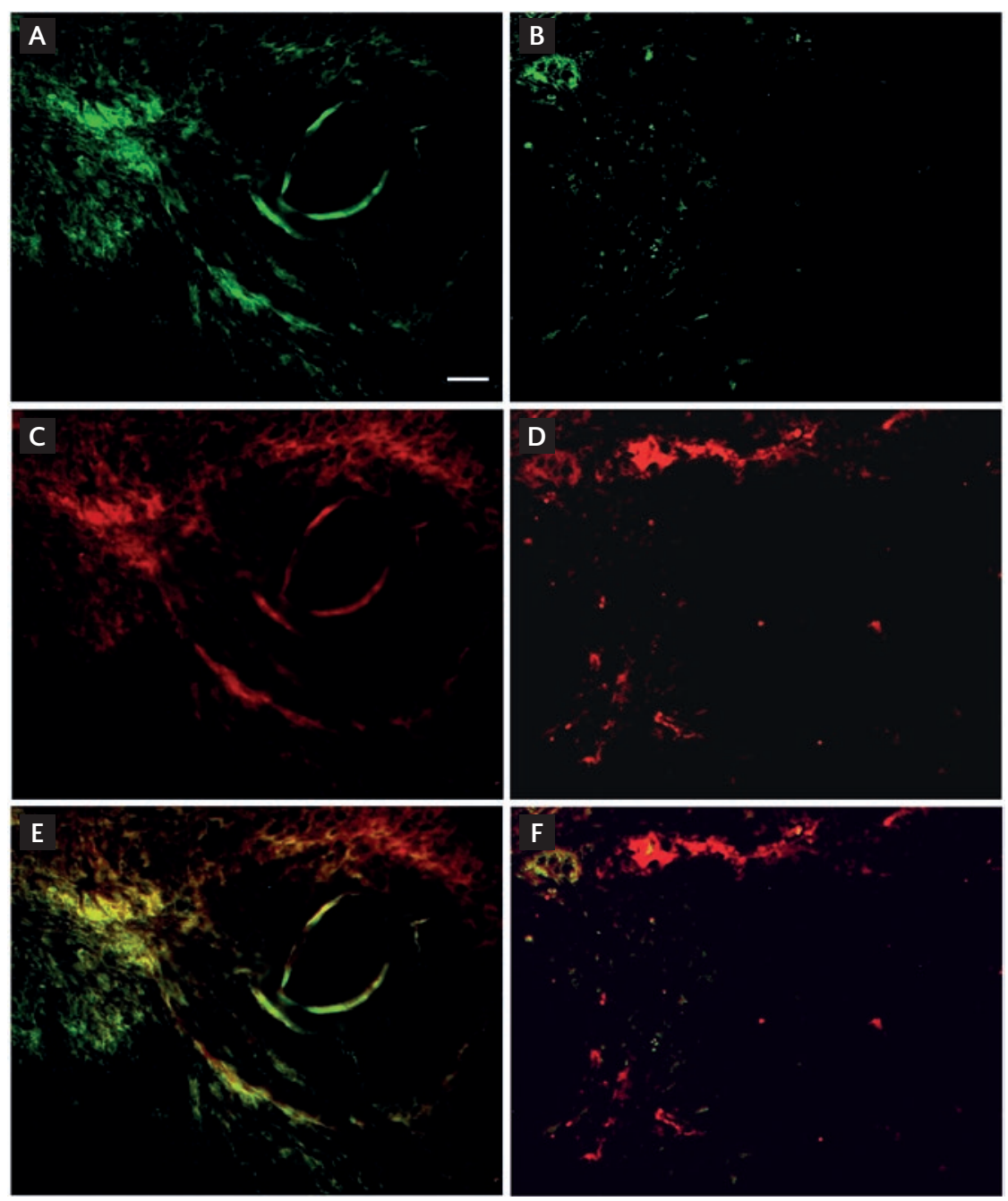

less active condition. In the present study, the proliferation of explanted tumors from nude mice was significantly inhibited by E3C1 gene therapy. Differences in regions showing cell death were evident between tumors in the control and E3C1-treated mice. Cell death in tumors in the control mice suggested that the parenchyma failed to obtain sufficient oxygen through the tumor vessels, whereas cell death in tumors in the E3C1-treated mice indicated apoptosis in the tumor stroma. Therefore, E3C1 treatment affected the tumor stroma.

In addition, the stroma in tumors in the $\mathrm{E} 3 \mathrm{C} 1$-treated mice was narrow compared with those in the control mice. The growth of stroma in the implanted tumor was thus considered to be inhibited by treatment with E3C1. The growth of tumor stroma may affect tumor growth, directly impacting prognosis. Tumor vessels are generally present in stroma and thus vessel growth would be poor in cases of inhibited stromal growth. The tumor parenchyma likely received insufficient oxygen and nutrients, indicating that E3C1 treatment inhibited the formation of tumor vessels, consistent with the observation of several transient decreases in tumor volume (Fig. 1C). Further, the staining ratio for aSMA was decreased by E3C1 treatment. aSMA is a marker of cancer stroma with a complicated relationship to prognosis ${ }^{29}$. Cases with a 
Figure 4. Effects of treatment with $\mathrm{E} 3 \mathrm{C} 1$ on tip cell generation. After gene therapy, specimens of the explanted tumors were stained for immunohistochemistry using anti-PECAM antibody (green) and anti-PDGF-beta antibody (red). Control (A, C and E) and pE3C1-treated tumors (B, D and F) on day 28. Magnification, 20x. Scale bars, $50 \mu \mathrm{m}$. (G) Relative fluorescence intensity of PDGF-beta-positive cells. The ratio for the E3C1 was taken as 1 . Results are expressed as mean \pm SD. ${ }^{* *} p<0.01$.
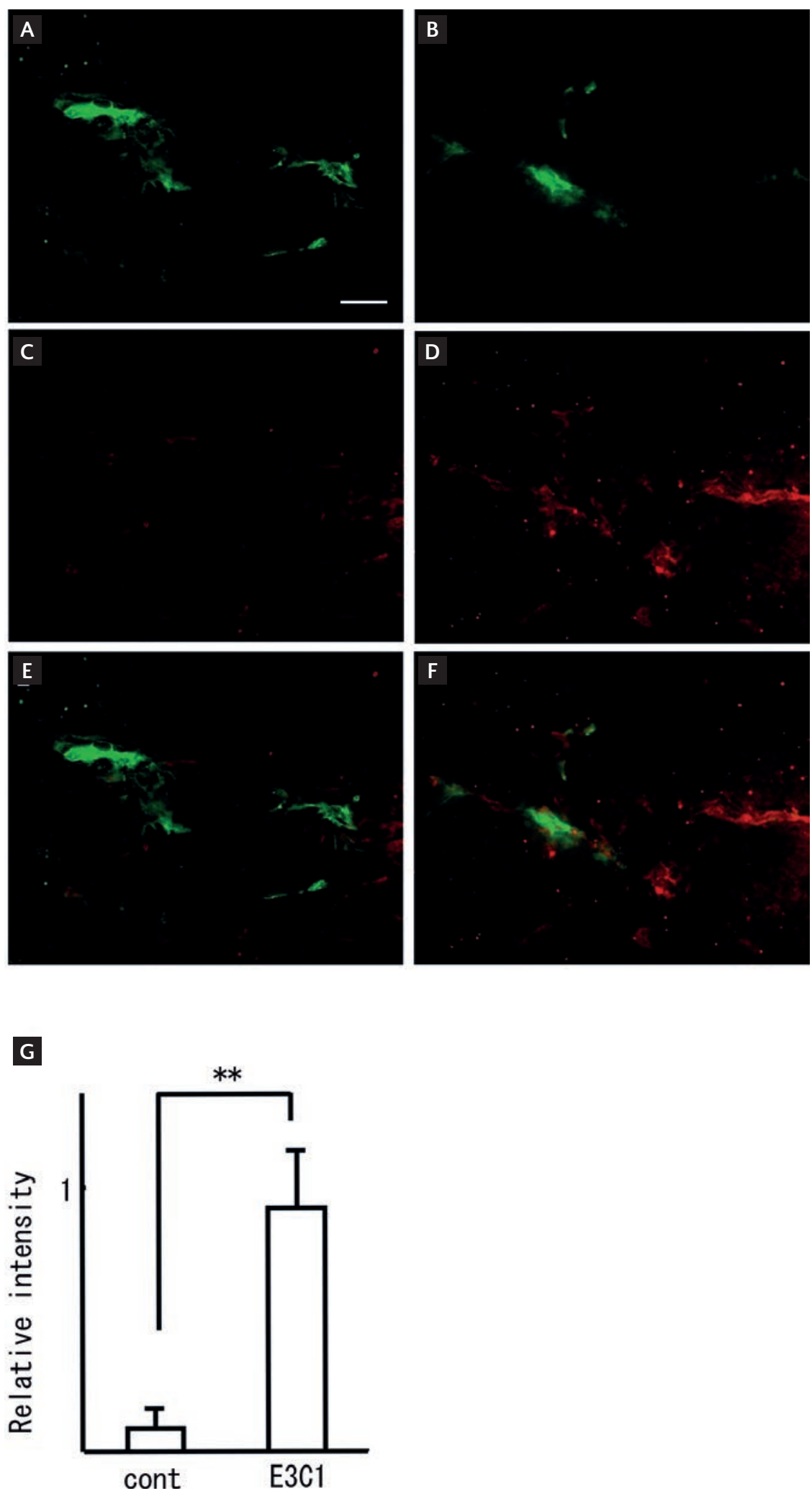
Figure 5. Expression of aSMA in the tumors. After gene therapy, specimens of the explanted tumors were stained for immunohistochemistry using anti-PECAM antibody (green) and anti-aSMA antibody (red). Control (A, C and E) and pE3C1-treated tumors (B, D and F) on day 28. Magnification, 20x. Scale bars, $50 \mu \mathrm{m}$. (G) Relative ratio of aSMA fluorescence intensity. The ratio for the controls was taken as 1 . Results are expressed as mean $\pm \mathrm{SD}$. ${ }^{* *} \mathrm{p}<0.01$.
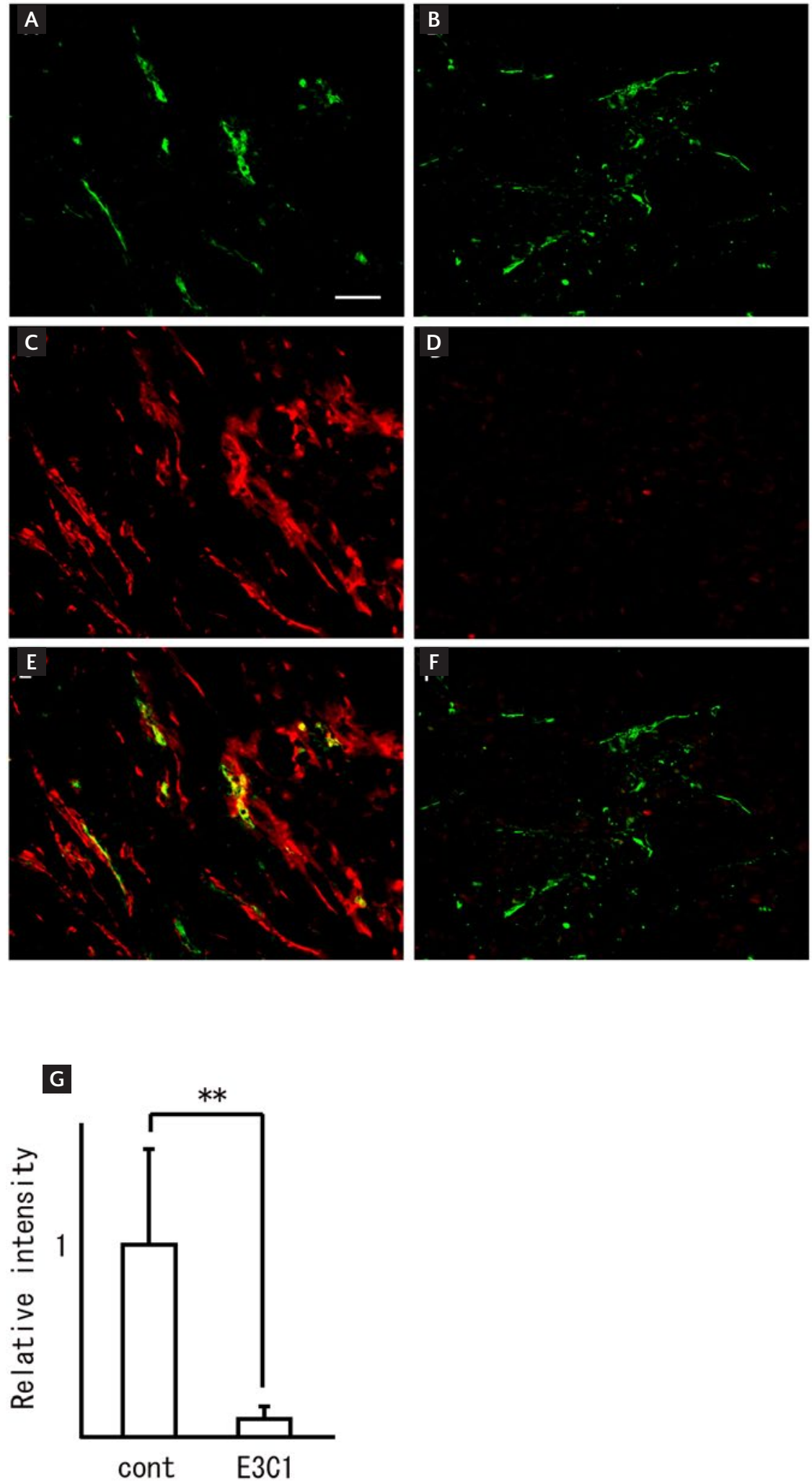
Figure 6. Expression of a-Notch and HEY1 protein. (A) Effects of E3C1 on active Notch (a-Notch) and a-Notch target gene (HEY1) as evaluated by western blot. HUVEC cells were treated with medium conditioned with AP-tag4 or AP-E3C1 for 5, 10, or 30 min. (B) Relative ratio of a-Notch density (white bars) and HEY1 (black bars). The ratio for the controls was taken as 1. Results are expressed as mean \pm SD. ${ }^{*} p<0.05,{ }^{* *} p<0.01$.
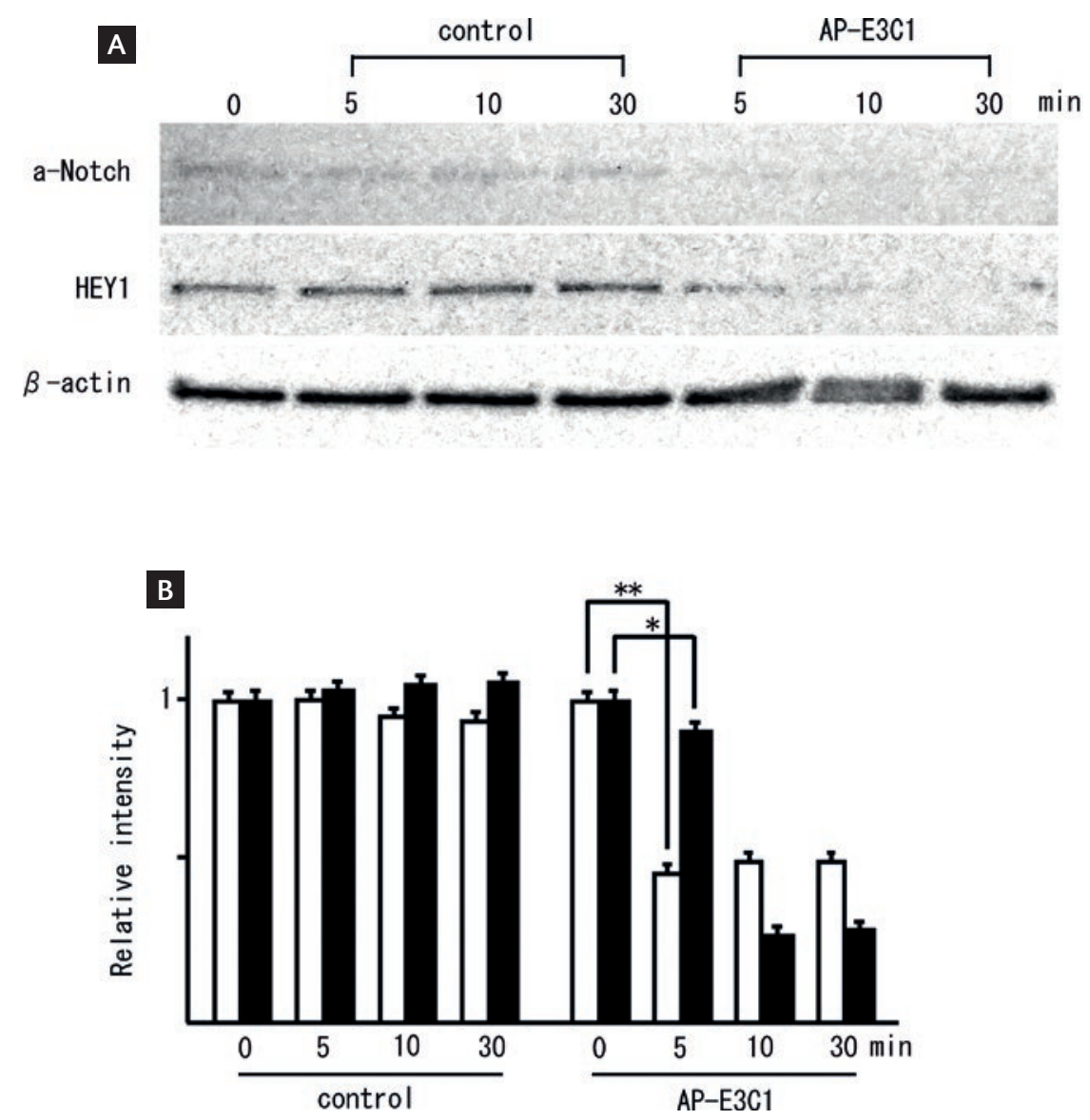

large volume of tumor stroma are believed to react poorly to chemotherapy or radiotherapy ${ }^{30}$. The tumor stroma might, therefore, show decreases in malignant characteristics following $\mathrm{E} 3 \mathrm{C} 1$ treatment.

Vessels without functional lumens in the E3C1-treated mice were identified in the tumor regions. Cells positive for PDGF, a marker of tip cells in angiogenesis, were increased in the E3C1-treated mice. Observation by electron microscopy revealed the patchy incorporation of endothelial cells and a loss of pericytes. Therefore, E3C1 therapy did not inhibit sprouting but did affect blood vessel maturation.

The expression of active Notch and HEY1 proteins decreases upon E3C1 treatment. The phenotype of the tumor vasculature after treatment with $\mathrm{pE} 3 \mathrm{C} 1$ is reportedly analogous to that after inhibition of Notch $^{31}$. The results of the present study suggest that the inhibition of effective angiogenesis is caused by E3C1 inhibiting Notch function. Decreases in Notch protein are associated with prognosis in human cancers $^{32}$. The EGF domain of Del1 has the amino acid sequence CXDXXXXYXCXC; interestingly, Notch has the same sequence ${ }^{33}$. The consensus sequence, CXDXXXXYXCXC, would presumably represent a key domain in the effects of E3C1 therapy inhibiting Notch function ${ }^{34}$.

In general, the major therapies for cancers are still surgical therapy, radiotherapy, and chemotherapy. However, patients not completely cured using these approaches require new therapies. Metronomic chemotherapy (MCHT) has recently attracted attention ${ }^{35}$. 
$\mathrm{MCHT}$ is a form of cytotoxic drug administration that differs from conventional chemotherapy schedules ${ }^{36}$ and involves the administration of low doses frequently or continuously (one-tenth to one-third of the maximum tolerated dose) of chemotherapeutic drugs over a long period. MCHT has the potential to greatly improve the quality of life of cancer patients. The inhibition of tumor vessel formation or stimulation of the anticancer immune response could be strategies for use along with $\mathrm{MCTH}^{37,38}$, and metronomic regimens could be considered for multi-targeted therapies. Cancer treatment with $\mathrm{E} 3 \mathrm{C} 1$ is, therefore, expected to contribute to the development of $\mathrm{MCTH}$.

The findings of this study confirmed that tumor treatment with E3C1 inhibits tumor growth, stromal growth in the tumor, and tumor angiogenesis. We previously reported the efficacy of tumor treatment with $\mathrm{E} 3 \mathrm{C} 1$ in two different squamous cell carcinoma lines ${ }^{13,18,39}$. The effects of $E 3 C 1$ in more types of squamous cell carcinoma lines need to be investigated in a future study. Furthermore, we intend to analyze the effects of $\mathrm{E} 3 \mathrm{C} 1$ on tumor stroma.

Vishal et al. ${ }^{40}$ reported that combination therapy with an angiogenesis inhibitor and chemotherapy has a 3.5 times higher risk of treatment-related mortality. In addition, fatal immune checkpoint inhibitor-associated toxic effects caused by this regimen have been reported ${ }^{41}$. Moreover, the prolongation of progression-free survival does not necessarily lead to an increase in quality of life. Establishing regimens for cancer treatment using $\mathrm{E} 3 \mathrm{C} 1$ should, therefore, be given careful consideration.

\section{ACKNOWLEDGEMENTS}

This work was supported by a Grant-in-Aid for Scientific Research from the Ministry of Education and Culture of Japan (22792019).

\section{REFERENCES}

1. Laura QM, Chow MD. Head and neck cancer. N Engl J Med. 2020;382:60-72.

2. Bray F, Ferlay J, Soerjomataram I, Siegel RL, Torre LA, Jemal A. Global cancer statistics 2018: GLOBOCAN estimates of incidence and mortality worldwide for 36 cancers in 185 countries. CA Cancer J Clin. 2018;68:394-424.
3. Siegel R, Ma J, Zou Z, Jemal A. Cancer statistics, 2014. CA Cancer J Clin. 2014;64:9-29.

4. Koch FP, Kunkel M, Biesterfeld S, Wagner W. Diagnostic efficiency of differentiating small cancerous and precancerous lesions using mucosal brush smears of the oral cavity-a prospective and blinded study. Clin Oral Investig. 2011;15:763-9.

5. Chan AT, Teo PM, Ngan RK, Leung TW, Lau WH, Zee B, et al. Concurrent chemotherapy-radiotherapy compared with radiotherapy alone in locoregionally advanced nasopharyngeal carcinoma: progression-free survival analysis of a Phase III randomized trial. J Clin Oncol. 2002;20:2038-44

6. Kwong DL, Sham JS, Au GK, Chua DT, Kwong PW, Cheng AC, et al. Concurrent and adjuvant chemotherapy for nasopharyngeal carcinoma: a factorial study. J Clin Oncol. 2004;22:2643-53.

7. Wee J, Tan EH, Tai BC, Wong HB, Leong SS, Tan T, et al. Randomized trial of radiotherapy versus concurrent chemoradiotherapy followed by adjuvant chemotherapy in patients with American joint committee on cancer/international union against cancer stage III and IV nasopharyngeal cancer of the endemic variety. J Clin Oncol. 2005;23:6730-8

8. Lee AW, Tung SY, Ngan RK, Chappell R, Chua DT, Lu TX, et al. Factors contributing to the efficacy of concurrent-adjuvant chemotherapy for locoregionally advanced nasopharyngeal carcinoma: combined analyses of NPC-9901 and NPC-9902 trials. Eur J Cancer. 2011;47:656-66.

9. Adelstein D, Gillison ML, Pfister DG, Spencer S, Adkins D, Brizel $\mathrm{DM}$, et al. NCCN Guidelines insights: head and neck cancers, version 2.2017. J Natl Compr Canc Netw. 2017;15:761-70.

10. Culver K, Cornetta K, Morgan R, Morecki S, Aebersold P, Kasid $A$, et al. Lymphocytes as cellular vehicles for gene therapy in mouse and man. Proc Natl Acad Sci U S A. 1991;88:3155-9.

11. Morecki S, Karson E, Cornetta K, Kasid A, Aebersold P, Blaese $\mathrm{RM}$, et al. Retrovirus-mediated gene transfer into CD4+ and CD8+ human T cell subsets derived from tumor-infiltrating lymphocytes and peripheral blood mononuclear cells. Cancer Immunol Immunother. 1991;32:342-52.

12. Kitano H, Mamiya A, Hidai C. Improvement of FasL gene therapy in vitro by fusing the FasL to Del1 protein domains. In: Yong $\mathrm{P}$, Rijeka $\mathrm{Y}$, editors. Targets in Gene Therapy. Croatia: InTech; 2011. p. 147-58

13. Kitano H, Mamiya A, Kokubun S, Hidai C. Efficient nonviral gene therapy with FasL and Del1 fragments in mice. J Gene Med. 2012;14:642-50.

14. Hidai C, Zupancic T, Penta K, Mikhail A, Kawana M, Quertermous $\mathrm{EE}$, et al. Cloning and characterization of developmental endothelial locus-1: an embryonic endothelial cell protein that binds the alphavbeta3 integrin receptor. Genes Dev. 1998;12:21-33.

15. Kitano H, Hidai C, Kawana M, Kokubun S. An epidermal growth factor-like repeat of Del1 protein increases the efficiency of gene transfer in vitro. Mol Biotechnol. 2008;39:179-85.

16. Mamiya A, Kitano H, Takao K, Kokubun S, Komiya M, Hidai C. An epidermal growth factor motif from Del1 protein increases the efficiency of in vivo gene transfer with a non-viral vector. Mol Biotechnol. 2013;54:445-50.

17. Hidai C, Kawana M, Kitano H, Kokubun S. Discoidin domain of Del1 protein contributes to its deposition in the extracellular matrix. Cell Tissue Res. 2007;330:83-95

18. Kitano H, Mamiya A, Ishikawa T, Egoshi K, Kokubun S, Hidai C. Long-term gene therapy with del1 fragment using nonviral vectors in mice with explanted tumors. Onco Targets Ther. 2016 9:503-16

19. Cully M. Cancer: tumour vessel normalization takes centre stage. Nat Rev Drug Discov. 2017;16:87.

20. Park JS, Kim IK, Han S, Park I, Kim C, Bae J, et al. Normalization of tumor vessels by tie 2 activation and ang 2 inhibition enhances drug delivery and produces a favorable tumor microenvironment. Cancer Cell. 2017;31:157-8.

21. Hendrix MJ, Seftor EA, Hess AR, Seftor RE. Vasculogenic mimicry and tumour-cell plasticity: lessons from melanoma. Nat Rev Cancer. 2003;3:411-21.

22. Wagenblast E, Soto M, Gutiérrez-Ángel S, Hartl CA, Gable AL, Maceli AR, et al. A model of breast cancer heterogeneity reveals vascular mimicry as a driver of metastasis. Nature. 2015; 520:358-62

23. Holash J, Maisonpierre PC, Compton D, Boland P, Alexander CR, Zagzag D, et al. Vessel cooption, regression, and growth in tumors mediated by angiopoietins and VEGF. Science. 1999;284:1994-8.

24. Kuczynski EA, Yin M, Bar-Zion A, Lee CR, Butz H, Man S, et al. Co-option of liver vessels and not sprouting angiogenesis drives acquired sorafenib resistance in hepatocellular carcinoma. J Nat Cancer Inst. 2016;108:djw030. 
25. Angara $K$, Borin TF, Arbab AS Vascular mimicry: a novel neovascularization mechanism driving anti-angiogenic therapy (AAT) resistance in glioblastoma. Transl Oncol. 2017;10:650-60.

26. Torre P, Pérez-Lorenzo MJ, Alcázar-Garrido A, Flores Al. Cell-based nanoparticles delivery systems for targeted cancer therapy: lessons from anti angiogenesis treatments. Molecules. 2020;25:715.

27. Urade M, Ogura T, Mima T, Matsuya T. Establishment of human squamous carcinoma cell lines highly and minimally sensitive to bleomycin and analysis of factors involved in the sensitivity. Cancer. 1992;69:2589-97

28. Urade M, Ogura T, Mima T, Matsuya T. Acquisition of bleomycin (BLM) resistance in human squamous cell carcinoma transplantable in nude mice. Cancer J. 1990;3:192-6.

29. Sălan Al, Mărășescu PC, Camen A, Ciucă EM, Matei M, Florescu AM, et al. The prognostic value of CXCR4, $\alpha-S M A$ and WASL in upper lip basal cell carcinomas. Rom J Morphol Embryol. 2018;59:839-49

30. Yoshida GJ, Azuma A, Miura Y, Orimo A. Activated fibroblast program orchestrates tumor initiation and progression; molecular mechanisms and the associated therapeutic strategies. Int J Mol Sci. 2019:20:E2256.

31. Porcheri C, Meisel CT, Mitusadis T. Multifactorial contribution of Notch signaling in head and neck squamous cell carcinoma. Int J Mol Sci. 2019;20:E1520.

32. Zhu Q, Li J, Wu Q, Cheng $\mathrm{Y}$, Zheng $\mathrm{H}$, Zhan $\mathrm{T}$, et al. Linc-OIP5 in the breast cancer cells regulates angiogenesis of human umbilical vein endothelial cells through YAP1/Notch/NRP1 signaling circuit at a tumor microenvironment. Biol Res. 2020;53:5.
33. Kitano $\mathrm{H}$, Kokubun $\mathrm{S}$, Hidai $\mathrm{C}$. The extracellular matrix protein Del1 induces apoptosis via its epidermal growth factor motif. Biochem Biophys Res Commun. 2010;393:757-61.

34. Hidai C. EGF-like domains with a C-x-D-x(4)-Y-X-C motif. Open Access J Trans Med Res. 2018;2:66-70.

35. D'Ascanio M, Pezzuto A, Fiorentino C, Sposato B, Bruno P, Grieco $A$, et al. Metronomic chemotherapy with vinorelbine produces clinical benefit and low toxicity in frail elderly patients affected by advanced non-small cell lung cancer. Biomed Res Int. 2018;2018:6278403

36. Kim JY, Kim YM. Tumor endothelial cells as a potential target of metronomic chemotherapy. Arch Pharm Res. 2019;42:1-13.

37. Pasquier E, Kavallaris M, André N. Metronomic chemotherapy: new rationale for new directions. Nat Rev Clin Oncol. 2010; 7:455-65.

38. Maiti R. Metronomic chemotherapy. J Pharmacol Pharmacother. 2014;5:186-92.

39. Kitano $\mathrm{H}$, Ishikawa $\mathrm{T}$, Tamura E, Kokubun S, Hidai C. Efficient cancer gene therapy with a Del1 fragment administered by hypodermic injection in a mouse explanted tumor model. Trans Cancer Res. 2018:7:686-94.

40. Vishal R, Sanjakumar H, Shenhong W. Treatment-related mortality with bevacizumab in cancer patients: a meta-analysis. JAMA. 2011;305:487-94

41. Daniel YW, Joe-Elie S, Justine VC, Sunandana C, Christian M, Fe $Y$, et al. Fatal toxic effects associated with immune checkpoint inhibitors: a systematic review and meta-analysis. JAMA Oncol. 2018;4:1721-8. 